\title{
Public Art Design in the Urban Memorial Plaza Under Cultural Inheritance
}

\author{
Xiaojuan Hui \\ Nankai University Binhai College \\ Tianjin, China 300270
}

\begin{abstract}
This paper takes public artwork design as the main body to study how public art in the urban memorial plaza reflects the memorial significance, and at the same time serves as the carrier of urban cultural inheritance and development. The public art design is set when the original site reflects the memorial significance of the Tangshan earthquake, which is very monotonous to give people an excessive sense of coldness and distance. At the same time, the original site does not establish facilities for the bereaved families to pay tribute to the late and express their grief, and there are no records to focus on the occurrence time of the Tangshan Earthquake. The pertinence and utilization rate of site is low respectively and the memorial significance is not clear enough. In order to improve the utilization rate of the site, the author refers to the design methods of public art in many memorial plazas at home and abroad, and then sets up public artworks based on cultural inheritance in the site. It is hoped that they can not only display the memorial significance of the victims in the Tangshan Earthquake but also provide a public art facility for the bereaved families to pay tribute to the late and express their grief. At the same time, some digital data about the Tangshan Earthquake are reflected in the public art design, which makes the site has targeted memorial significance and reflects the inheritance and development of urban culture. When public art is integrated with the surrounding environment, it will give deeper meanings and connotation to the entire site and at the same time give people who come to the site a deeper sense of memorial meaning.
\end{abstract}

Keywords—memorial plaza; public art; cultural inheritance

\section{INTRODUCTION}

The memorial plaza is of great significance to contemporary people's life. When some major events occurred such as natural disasters, historical campaigns, major accidents etc., people need a site to express their grief, precipitate their emotions and encourage the later generations. So the study of the memorial plaza has its special significance. As part of the urban planning, it will make great contributions to the city invisibly. For example, the increase of the leisure and entertainment space of the city will generate positive emotions for people, and it will also promote local economic development, cultural inheritance and development and the development of the local tourism industry to a certain extent. Since the memorial plaza is a relatively serious space that psychologically invisibly brings to the people in the site a sense of oppression, and at the same time it leads to a relatively low utilization rate of the site. It is hoped that this situation will be alleviated by the design of the public art of the site, and the cultural inheritance of the urban memorial plaza will be better integrated with the daily leisure and relaxation of the citizens.

\section{DEFINITION OF RELATED CONCEPTIONS}

\section{A. Memorial Plaza}

The memorial plaza is dominated by urban historical and cultural sites and memorial buildings, or the establishment of prominent memorials in the plaza such as monuments, memorial towers and figure sculptures etc., with the main purposes to be admired by people. This kind of plaza should keep the environment quiet and forbid traffic flow to cross and disturb the inside plaza. ${ }^{1}$

\section{B. Cultural Inheritances}

Namely, the traditional culture integrated into modern design through the selection and digestion of modernity and modern design. Culture is the general terms of material and spiritual wealth created by human beings in the process of social development. Cultural inheritance refers to the process of transmission and inheritance of these two kinds of wealth between the upper and lower generations. ${ }^{2}$

\section{Public Art}

Public Art is a borrowed word, also known as public art or social art, which does not belong to a certain artistic genre or style, nor only refer to a certain kind of art form. However, it exists in public space and serves the public, which reflects a kind of spirit and value of cultural openness, sharing and communication in public space. Public art refers to the artistic creation and the corresponding environmental design in such a public open space. ${ }^{3}$

\footnotetext{
Yang Zhide. Memorial Landscape Design, Jiangsu Fenghuang (Phoenix) Science and Technology Press, July 2014.

Li Yanzu. Introduction to Art Design, Hubei Fine Arts Publishing House, March 1, 2009.

Zeng Guisheng, He Jinzhi. Public Art, Harbin Engineering University Press, January 1, 2009.
} 


\section{Public Art Design Methods In the Urban MEMORIAl PlaZA UNDER CUlTURAL INHERITANCE}

\section{A. Public Art Design Methods}

\section{1) Public art space modeling designs}

a) Public landscape modeling arts: Public landscape modeling arts roughly include logo modeling, square center modeling, advertising modeling, park artwork modeling, small architectural modeling, display modeling, plant modeling, and floor decoration modeling.

There are many design methods for public art in the plaza. First of all, one of the public arts is designed by extracting the prominent characteristics offered by the site or the character images and time-to-events in the memorial plaza and other elements. For example, the multi-group documentary figure sculptures set up in the Memorial Hall of the Nanjing Massacre Victims of the Japanese Invaders are designed to extract the image of the compatriots killed in the Nanjing Massacre and the actual conditions of events happened at the time. This kind of documentary public art design method can strongly highlight the theme of the site, and at the same time give a strong sense of reality and substitution, which can stimulate people's emotions. And through these lifelike sculptures, which can help people intuitively understand this phase of history, strengthen their spirit of patriotism and love for peace, and inspire their sense of happiness in the era of fundamental peace.

The public arts with symbolic features can drive the development of urban culture. Brussels' symbolic sculpture "Peeing Boy" is a public art with small size. If you first come to Brussels and you may be difficult to find it, but it is very famous. The reason why if you don't see it and you will feel like you haven't been to Brussels is that there is a remote story behind this sculpture. As it tells the history of the origin of the city of Rome, so this sculpture is the symbolic artwork of the city. The symbolic public arts can give people the most intuitive feelings, let people take the initiative to understand the contents behind artworks, and directly promote the development of urban cultural inheritance.

b) Public facility modeling art designs: Public facility modeling arts include: sanitary facility modeling, sports facility modeling, transportation facility modeling, communication facility modeling, amusement facility modeling, and modulator tube modeling.

The design of lighting in the plaza can set off by contrast the atmosphere of the whole plaza, which different colors and illuminance can interpret different atmospheres and express different site themes. At present, many technological touch lights are pushed out, and only when visitors touch the lights with their hands will the lights turn on, which can greatly improve the interactivity in the site, and bear more modern characteristics. Now there are many lighting exhibitions that are similar to those held by the Beijing 798 Cultural Center, the hall has no any facilities apart from the modulator tubes, and all the effects are reflected by lighting. The various patterns mapped by the lights give people a sense of future and science and technology.

\section{2) Public art plane modeling design}

a) Public mural art: Public mural arts mainly include: decorative murals, lacquer paintings, ceramic paintings, sign murals, pattern murals, character murals, animal murals, landscape murals. As for the art mural photos set by the subway station along the Beijing Metro Line 4, and the creepy ancient style murals and the Portuguese ceramic tile murals in Stockholm subway stations, large scale figure murals on their walls belong to public art. The forerunner of urban murals is Tony Garnier who is a visual artist in the 1920s. Lyon is France's famous "Mural Capital", when you stroll through Lyon, and you will find beautifully colorful murals on the walls of many buildings here, which can be more attractive to people's attention and make people more active in understanding the hided design background of public art works.

b) Public decoration relief art: Relief mainly includes: wood relief, metal relief, memorial relief, stone relief, glass relief, thematic relief, decorative relief, and abstract relief. Relief can appear in different public environments in different forms and it can be used as a carrier of stories. In memorial plaza, relief can be used to show the public the scene of a certain event, which can make the public more intuitive to the process of event, thus making the real situation of the events reappear.

3) New media public art design: With the rapid development of science and technology, designers can complete more ideas on public art design through science and technology. Located in Chicago's Millennium Park, the Crown Fountain, as a permanent outdoor art work, boldly uses new media artistic installations to design public art. The main part of public arts here are no longer the choice of traditional public art design elements such as marble or metal, but they are designed with the combination of water, large display screen, LED and other elements with the entire construction cost reached $\$ 17$ million. The styling of the Crown Fountain is quite modern, and the main part of this work is two electronic towers with a height of 15.2 meters, which is covered with LED lights. The corresponding two sides have two huge display screens, which play various kinds of different things that are the human face with the expression of spit water and at the same time the water spray decoration is set in the mouth part, thus forming a fountain. Such public art designed with new media enhances the sense of modern of the site and enhances interactivity.

\section{B. Public Art Design Principles}

The principles that public art should pay attention to in the design process roughly include spatial integration principle, humanistic regionalism principle and public aesthetics principle.

1) Spatial integration principle: Spatial integration refers to the sense of order and functionality that are highlighted by spatial location, spatial characteristics and spatial architecture. The various public arts in the city convey to the public the symbolic significance of the importance of a particular building or place. The degree of spatial integration represents the efficiency of space use. The high degree of 
integration indicates that the utilization of the space is high, which is a place where people flow and traffic stream are dense.

The memorial plaza is more rigorous in terms of layout pattern than the ordinary urban leisure plaza. Most of the memorial plazas choose the planning center point layout pattern, and especially the memorial area in the plaza, which should be located on the main road and the central axis of the plaza. On the site's topography, the theme memorial public art should be located at the highest point of the site, which usually is accompanied by steps or platforms. The central point layout is the most common layout method in the memorial plaza.

2) Humanistic regionalism principle: On the one hand, the design of public art should conform to the basic spatial function, and on the other hand, it bears the function of spreading regional culture. The design of public art that conforms to the humanistic regional characteristics is the key to promoting the development of the entire public space. Good public art should be based on geography, history and cultural cities. And it should combine them and fully reflect the spiritual characteristics of specific time and space, which makes public art better integrate the public's daily life. Public art combines with the daily leisure activities of the public, focuses on regional culture, and of which seeking the beauty of art is the most important point, so that the public art can both be appreciated by the public and play the role of spreading the urban culture.

The memorial plaza is a place where the city's style and features, cultural connotation and landscape features are concentrated. The public art in the memorial plaza not only reflects the highlight of the theme of the memorial events, but also contains the humanistic regional characteristics of the place where the event occurred, which reflects the development of cultural inheritance. While emphasizing the embodiment of the humanistic regional characteristics, it is actually strengthening the memorial theme of the site, and inheriting and developing the memorial theme culture.

3) Public aesthetic principles: The creation of public art includes the inheritance of tradition and personal creativity. In the public space, the expression methods of public art should meet the needs of the public in the face of different social classes, educational backgrounds, nationalities, and customs. As an important issue in public art design, public aesthetic in the process of public art design emphasizes the commonality of aesthetics, and the harmonious degree of the working environment and the public aesthetic, which makes the public not only observes the environment, but also participates in and experiences the aesthetics.

The above three principles are the basic principles of public art in the design process. Only by meeting the above three design principles can we design public art that meets the aesthetic requirements of the public and promotes the inheritance and development of urban culture.

\section{Practice of Public ARt DESIGN In MEMORIAL PLAZA}

The practice of the project is located in anti-seismic monument in Tianjin, which is used to commemorate the compatriots who were killed in the 8.2 magnitude Tangshan Earthquake that occurred at 03:42:58 Beijing time on July 28 , 1976. The monument that is made of four pieces of arched right-angled triangular granite is pyramid-shaped, which is wide under and narrow above, meaning wisdom, strengths, and prospects. The four supporters represent stability and support from all directions. At the same time they also mean thanks to all sides for their support to Tianjin. The whole height of this monument is 19.76 meters, which symbolizes the occurrence time of the Tangshan earthquake being 1976. From all aspects, the monument looks like a "human" shape, which is a "ten" shape looked from the air. This kind of design means that people will win the nature and reflect the strength of the people can rebuild their homes and build a new Tianjin. At the top of the monument have three characters that represent workers, peasants, and soldiers respectively.

In response to the renovation and design of the antiseismic monument in Tianjin, this paper uses the central point layout method to design because the base is now only a monument public artwork, which is located in the middle of the site, and this paper also adopts the spatial integration principle of the memorial plaza public art. The relief design on the monument can strongly express the scene of the people who fight the disaster with one heart and inspire the morale of the people, which reflects the spirit of our people who are not admit defeat before the disaster and are not afraid of suffering. The three characters that represent workers, peasants, and soldiers respectively, which express the people of all works of life in China are brave enough to resist earthquakes and go all out to participate in postdisaster construction.

The design of the monument has played an inspiring role in the spiritual field and played a very good role on cultural inheritance. However, as the main public artwork in the site it lacks prominent memorial significance for the Tangshan Earthquake and its memorial theme is not reflected clearly. In the performance of cultural inheritance, the memorial figures, dates, time, etc. have the most intuitive effect on the thematic expression of the memorial events. Therefore, in the process of the project transformation, the author adds light strips with the shape of " 7.28 " to the monument, which bring the commemoration of the time of the disaster, so that the site's memorial theme can be much clearer.

In the memorial plaza, it should establish a place for bereaved families to express their grief and add landscape walls in the site decorated with light strips of seismic crack morphology to highlight memorial theme. Some stories and heroic deeds happened during the Tangshan Earthquake are engraved on the memorial landscape walls. The monumentality of the site can be much clearer through the setting of landscape walls, which not only enriches the use function of the site, but also makes the function more complete and plays a role in culture inheritance. The design 
of the light strip running through the whole ground of the site is inspired by the morphology of the seismic crack. The light strips on the ground echo the light strips on the wall, which unify the commemorative theme of the whole site and give full play to the memorial expression of the Tangshan Earthquake.

\section{CONCLUSION}

We understand the different classifications of public arts and various design forms of public arts included by different classifications through this paper's research on the public art of memorial plazas. The public arts often used in memorial plaza have the same attributes, which are dominated by sculptures and relief of the character images, murals used to record memorial stories, monuments and others.

We shall follow three design principles in the process of public art designs, namely, spatial conformity principle, cultural regionalism principle and public aesthetic nature principle. Public artworks that only meet the three abovementioned principles are integrated. Public artworks that are conform to social development principle on the one hand and are excellent on the another hand can not only play an effect of beautifying sites, but only serve as a vehicle for the inheritance and development of urban culture at the same time. The memorial public artworks shall highlight the memorial theme of sites and spiritually play a positive and initiative role on people.

The author applies the memorial plaza public art design techniques learned from previous investigations and researches to this case transformation, which make the memorial theme of this case more explicit and can increase the utilization rate of site. In order to highlight the memorial pertinence of the Tangshan Earthquake, the original site will be marked by adding light stripes of seismic crack morphology, landscape walls of memorial theme, and adding memorial figures of disaster occurrence time on the existing monuments.

\section{REFERENCES}

[1] Yunfu. Greatness lies in the capacity. Lingnan Fine Arts Publishing House, December 2001. Page 51, 101, 65. (in Chinese)

[2] Eugen Habermas. Public Sphere Translated by Wang Hui, Load Culture and Publicity, Sanlian (Trigeminy) Bookstore, Page 125. (in Chinese)

[3] Please refer to Eugene Habermas. The Structural Transformation of the Public Sphere, translated by Cao Weidong, Shanghai, Xuelin Publishing House. (in Chinese)

[4] Panofsky. The meaning of Visual Art, translated by Fu Zhiqiang, Liaoning People's Publishing House, Page 124 . (in Chinese)

[5] Li Kairan. Introduction to Landscape Monumentality. Beijing: China Architecture Industry Press, 2005. (in Chinese)

[6] Li Shuidi. Red Culture and Inheritance. Nanchang: Jiangxi People's Publishing House, 2009. (in Chinese)

[7] Renjun. Architectural Memorial Interpretation Memorial Noumenon and Memorial Aesthetic Research. Beijing, China Federation of Literature and Art Publishing House, 2006. (in Chinese)

[8] Habermas. Structural Transformation of the Public Sphere [M]. Translated by Cao Weidong, Wang Xiaojue, Liu Beicheng, etc. Shanghai Xuelin Publishing House, 1993-3. (in Chinese)
[9] Mu. Boii HuS' Conversation with Visitors [J]. World Art, 1996 (2): 19-23.

[10] Lewis Mumford. Urban Development History-origin, Evolution and Prospect $[\mathrm{M}]$. Translated by Song Junling, Ni Wenyan. Beijing: China Architecture Industry Press, 1989: 74. (in Chinese)

[11] Sun Zhenhua. The age of public art. Jiangsu Fine Arts Publishing House. (in Chinese)

[12] (French) Catherine - Gru. Art Intervention Space. Guangxi normal University Press.

[13] (UK) Brian Lawson. The Language of Space. China Architecture Industry Press.

[14] Yin Dingbang. Introduction to Design Studies. Hunan Science and Technology Press, August 1999. Page 182. (in Chinese)

[15] Zou Wen. Public Art in Beijing. Decoration. No. 10, 2002. (in Chinese) 